\section{TRAJETÓRIA NO BASQUETEBOL E PERFIL SOCIODEMOGRÁFICO DE ATLETAS BRASILEIRAS AO LONGO DA CARREIRA: UM ESTUDO COM A LIGA DE BASQUETE FEMININO (LBF)}

BASKETBALL TRAJECTORY AND SOCIODEMOGRAPHIC PROFILE OF BRAZILIAN ATHLETES THROUGHOUT THEIR CAREERS: A STUDY ABOUT THE WOMEN'S BASKETBALL LEAGUE (LBF) C?

TRAYECTORIA EN EL BALONCESTO Y PERFIL SOCIODEMOGRÁFICO DE ATLETAS BRASILEÑAS A LO LARGO DE SUS CARRERAS: UN ESTUDIO CON LA LIGA DE BALONCESTO FEMENINO (LBF) C

doi' https://doi.org/10.22456/1982-8918.106017

(D) Larissa Rafaela Galatti* <lgalatti@unicamp.br>

iD Cesar Vieira Marques Filho*<cesarvmf@hotmail.com>

Yura Yuka Sato dos Santos* <yura_sato@hotmail.com>

iD Guilherme Watoniki* <guilhermesouzawatoniki@outlook.com>

iD Paula Korsakas* <pkorsakas@gmail.com>

D Luciano Allegretti Mercadante*<lucianomerc@yahoo.com.br>

*Universidade Estadual de Campinas. Campinas, SP, Brasil.

Resumo: Após os anos 2000, observamos um cenário desafiador ao desenvolvimento de mulheres atletas de basquetebol no Brasil. Em 2010, a Liga de Basquete Feminino (LBF) foi criada para contribuir com a reestruturação da modalidade no país. O objetivo do estudo foi investigar indicativos esportivos e sociodemográficos ao longo da carreira de atletas da LBF 2018. Os dados foram coletados por um questionário online respondido voluntariamente por 57 atletas (média de idade 25,9 $\pm 6,6$ anos). A escola foi o principal local de primeiro contato com a modalidade. A maioria das atletas $(79 \%)$ foi convocada para seleções e $30 \%$ chegaram à seleção adulta. O Sudeste se destacou como a principal região de prática da modalidade. A carreira no basquetebol proporcionou percepção de melhoria de classe social. Por fim, o grupo de atletas apresentou níveis de escolaridade mais altos do que a média da população brasileira.

Palavras chave: Basquetebol. Mulheres. Prática Profissional.
Recebido em: 31 jul. 2020 Aprovado em: 01 dez. 2020 Publicado em: 18 fev. 2021

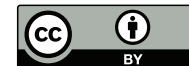

Este é um artigo publicado sob a licença Creative Commons Atribuição 4.0 Internacional (CC BY 4.0).

elSSN: 1982-8918 


\section{INTRODUÇÃO}

Apesar dos avanços ao longo das décadas, historicamente meninas e mulheres brasileiras têm enfrentado dificuldades para praticar esporte, incluindo um período de proibição pela ditadura de algumas modalidades até o ano de 1979 (BRASIL, 1941). Este histórico construiu cenários de preconceitos, falta de estrutura, menores investimentos e pouca visibilidade na mídia até os dias atuais, evidenciando que o esporte feminino e seus feitos seguem sendo marginalizados (GOELLNER, 2014; GIGLIO et al., 2018).

Ainda que o basquetebol não tenha estado dentre as modalidades proibidas por decretos legais até 1979 - como aconteceu com outros esportes, como futebol, futsal e polo aquático -, existem relatos históricos de barreiras sociais para a prática por atletas naquele período, mesmo daquelas que fizeram parte das seleções brasileiras que conquistaram dois ouros nos Jogos Pan-americanos de 1967 e 1971, ou a medalha de bronze no mundial de 1971 (GUEDES, 2009). Curiosamente, além do basquetebol não ter sido proibido, o Brasil ainda sediou o campeonato mundial em 1971, em um lotado ginásio do Ibirapuera, o que surpreendeu inclusive as atletas (GUEDES, 2009)¹.

Na década de 1990, mesmo sem um cenário interno com competições estruturadas ou clubes/instituições estáveis para o desenvolvimento de atletas de basquetebol no Brasil (GALATTI et al., 2015), o país se tornou potência mundial entre as mulheres, conquistando o Pan-americano em Cuba (1991), o campeonato mundial na Austrália (1994) e as medalhas olímpicas de prata (Atlanta, 1996) e bronze (Sidney, 2000). Em 2004, nos Jogos Olímpicos de Atenas, e em 2006, em novo mundial sediado no Brasil, a seleção brasileira conquistou a quarta posição. No entanto, mais recentemente, nos Jogos Olímpicos de Pequim 2008 e Londres 2012, a equipe ocupou a décima primeira e nona colocações, respectivamente. Na edição do Rio 2016, a seleção brasileira ficou com a penúltima colocação e em 2018 não se classificou para o Campeonato Mundial da Espanha. Mesmo voltando a conquistar um título intercontinental, o Pan-americano de 2019, atualmente o basquetebol feminino nacional se encontra na $15^{a}$ colocação no ranking da FIBA (FIBA, 2020).

No cenário nacional, seguimos observando a falta de oferta da modalidade para meninas e mulheres, e o declínio de resultados parece ter vindo acompanhado da redução ainda maior do número de meninas e jovens praticantes (ANTONELLI et al., 2012; GALATTI et al., 2015). O clube é o local clássico de desenvolvimento do basquetebol masculino, mas poucos possuem equipes femininas, sugerindo que as instituições públicas e projetos sociais tenham papel importante nessa oferta (BENELI; GALATTI; MONTAGNER, 2017). Este contexto levanta perguntas sobre o desenvolvimento da modalidade e as oportunidades das meninas acessarem um processo de formação de atletas.

A falta de oferta e de praticantes de basquetebol feminino brasileiro ilustra um cenário mais amplo, em que as oportunidades para prática esportiva de meninas e mulheres são marcadas por desigualdades presentes no acesso ao esporte nos seus

\footnotetext{
1 Para acesso aos depoimentos e aprofundamento sobre as vivências das atletas brasileiras de basquetebol dos primeiros anos até este mundial, recomendamos o livro de GUEDES (2009), Mulheres à Cesta: O Basquetebol Feminino no Brasil (1892-1971).
} 
diferentes níveis, da prática recreativa ao esporte de alto rendimento, em comparação com aquelas oferecidas aos meninos e homens (PNUD, 2017). Isso se reflete em outros papéis, como a baixa participação de mulheres como treinadoras ou árbitras, mesmo na Liga de Basquete Feminino (PASSERO et al., 2019).

Este cenário interfere no desenvolvimento da modalidade no país e dificulta a captação de investimentos e de patrocinadores, bem como a formação de equipes profissionais (GITTI; BASTOS, 2013; MORALES JÚNIOR et al. 2017), além de se mostrar desfavorável ao desenvolvimento da carreira de atletas de basquetebol feminino. A carreira esportiva pode ser descrita como uma atividade destinada a alcançar o máximo desenvolvimento pessoal em uma modalidade esportiva, desde a iniciação, passando pelas etapas de desenvolvimento/especialização, aperfeiçoamento, manutenção, até a descontinuação e aposentadoria da atleta. A carreira esportiva pode se desenvolver no âmbito local, regional, nacional ou internacional, ou ainda, amador ou profissional (ALFERMANN; STAMBULOVA, 2007; CÔTÉ et al., 2009; STAMBULOVA et al., 2009).

Para chegar aos níveis mais elevados - nacional e internacional - as atletas precisam de dedicação e oportunidades: além da dedicação aos ambientes de treinamento e às atividades que levam ao aperfeiçoamento e à manutenção do rendimento, atletas rumo a uma elite nacional também são influenciadas pelo cenário em que estão inseridas. Logo, os aspectos contextuais como os sociodemográficos são indissociáveis da trajetória esportiva de uma atleta (CÔTÉ; TURNNIDGE; EVANS, 2014). Souza e Martins (2018), por exemplo, apontaram que a carreira no futsal feminino é pouco estruturada e o perfil é de mulheres de famílias de baixo capital cultural e poder aquisitivo. As autoras verificaram que o futsal apresenta uma relação de paradoxo às atletas, pois mesmo sem perspectiva de carreira esportiva sólida, a partir do futsal conseguem acesso ao ensino superior e, consequentemente, formação para uma profissão melhor que a própria carreira no futsal. Samulski et al. (2009), por sua vez, identificaram que conflitos para a realização da prática e a falta de planejamento dificultaram o ótimo desenvolvimento de carreira esportiva de atletas brasileiros de alto rendimento. Barreiras como falta de infraestrutura, de assistência governamental e de patrocínio e desvalorização de algumas modalidades esportivas também foram identificadas por Rocha e Santos (2010).

Além dos aspectos já mencionados, outros, como políticas públicas e gestão esportiva, neste caso de uma liga de basquetebol feminino, podem representar apoio ou dificuldade para a inserção e manutenção da carreira esportiva de atletas. Dessa maneira, torna-se importante conhecer quem são as atletas que uma liga é capaz de atrair, suas origens e trajetórias esportivas, além de elementos sociodemográficos que contribuam com o desenho de melhores condições de desenvolvimento de carreira para as atletas. Em 2010, com o intuito de colaborar para a reestruturação do basquetebol feminino, teve início a Liga de Basquete Feminino (LBF), tornando-se responsável pelo principal campeonato de basquete feminino de elite do Brasil. Beneli (2018) aponta que a criação da LBF contribuiu para a valorização da modalidade, ampliação do número de equipes participantes, melhoria das condições de trabalho e aumento da visibilidade. 
Com a intenção de impulsionar o desenvolvimento do basquete feminino de elite no Brasil a partir de evidências científicas, a LBF estabeleceu convênio com a Faculdade de Ciência Aplicadas da Universidade Estadual de Campinas (FCA/UNICAMP). Compreender quem são e qual o percurso esportivo das atletas que compõem a LBF pode oferecer indicativos para seu crescimento e para que a Liga possa propor ações que contribuam em melhores condições de acesso e desenvolvimento de carreira esportiva de mulheres no basquetebol brasileiro. Também é importante conhecer se a LBF absorve atletas que passaram pelas seleções nacionais de base, tanto quanto se ela absorve atletas da seleção brasileira adulta. Somado a isto, é relevante compreender se atuar na LBF provê às atletas sustento e independência financeira, visto que a falta de perspectiva de carreira é um dos fatores associados à desistência (GALATTI et al. 2015; LIMA, 2018b; PAIM; STREY, 2006), logo, são considerados indicativos importantes para o desenvolvimento da carreira: faixa salarial, percepção de melhoria de classe social, continuidade nos estudos e perspectiva de ter uma profissão futura.

Na última década, houve um crescimento no interesse por pesquisas incluindo a trajetória de atletas mulheres no Brasil (BENELI; GALATTI; MONTAGNER, 2017; BARREIRA et al., 2018; COLLET et al., 2017; LIMA, 2018; GALATTI et al., 2019; MASCARIN, VINCENTINI e MARQUES, 2019). Mascarin, Vicentini e Marques (2019) investigaram o processo de desenvolvimento da carreira esportiva de jogadoras brasileiras de elite do futsal e identificaram que elas iniciaram a prática sistemática mais tarde que os atletas homens, receberam incentivo mínimo para praticar futsal na escola ou em clubes, e perceberam preconceito sobre os estereótipos de gênero. Beneli, Galatti e Montagner (2017) investigaram as características socioesportivas de 28 atletas das seleções brasileiras de basquete sub-19 e adulta e identificaram que as atletas vinham de famílias com condição financeira "baixa", tiveram apoio da família para prosseguir na carreira, e que o início da prática foi pouco diversificado, tardio em relação à literatura, mas precoce em competições de nível estadual e nacional. No entanto, desconhecemos estudos que tenham oferecido um panorama das atletas envolvidas em uma temporada de uma liga esportiva de basquete, considerando tanto elementos de sua trajetória esportiva, como condição salarial e auxílios para o desenvolvimento de carreira. Isto posto, o objetivo foi investigar indicativos esportivos e sociodemográficos ao longo da carreira de atletas da LBF. Como objetivos específicos, buscamos identificar junto às participantes: (i) local de acesso à modalidade; (ii) idades de início, primeira competição e acesso à competição na categoria adulta; (iii) convocações para seleções nacionais de base e adulta; (iv) auxílios disponíveis, faixa salarial e percepção de classe social; (v) escolaridade e presença de perspectiva de profissão pós-carreira esportiva.

\section{METODOLOGIA E MÉTODOS}

Este é um estudo de caso, que investiga um fenômeno contemporâneo dentro de seu contexto (YIN, 2005) e possibilita uma visão mais clara de um fenômeno pouco conhecido (GIL, 2009). Por conta do elevado volume de participantes da pesquisa, bem como do distanciamento geográfico entre elas, a opção se deu pela utilização 
de um questionário para a coleta de dados, visto que este instrumento permite recolher uma alta gama de informações, ainda que sem a mesma profundidade proveniente da utilização concomitante de outros instrumentos (ANDRADE, 2009). O questionário de caráter retrospectivo (CÓTÉ; ERICSSON; LAW, 2005) teve por base os instrumentos aplicados por Cunha et al. (2017) e Beneli (2018), sustentado em Cafruni, Marques e Gaya (2006), Marques e Samulsky (2009) e Marques et al. (2014), sendo as adaptações feitas por consenso (ALVES-MAZZOTTI, 2006) ao longo de três reuniões entre cinco pesquisadores: dois doutores e três pós-graduandos em nível de doutorado. A aplicação foi no período de março a maio de 2018, no formato online, por meio do "formulário Google", composto por 30 questões. As questões abordaram a trajetória até a categoria adulta (dados I) e trajetória na categoria adulta (dados II), abordando temas como:

Dados I: Trajetória até a categoria adulta

- Dados Pessoais: Local de nascimento (cidade, estado), data de nascimento.

- Escolaridade I: Nível de escolaridade até ingressar na categoria adulta.

- Início da prática de basquetebol: cidade onde começou a praticar, cidade onde começou a competir, local (clube, escola, projeto social) e idade.

- Perfil Socioeconômico I: Percepção da classe social quando começou a competir e auxílios financeiros recebidos até ingressar na categoria adulta.

- Convocação para seleções nacionais de base.

Dados II: Trajetória na categoria adulta

- Início em competições adultas: Idade, cidade e equipe.

- Participações na LBF: Ano e clube.

- Convocação para a seleção nacional adulta.

- Perfil Socioeconômico II: Percepção da classe social atual e remuneração atual.

- Escolaridade II: Nível de escolaridade e detalhamento da situação atual.

- Carreira e Pós-carreira: Expectativa de duração da carreira e planos para o póscarreira.

\subsection{ASPECTOS ÉTICOS}

O projeto teve a aprovação do Comitê de Ética em Pesquisa da Universidade Estadual de Campinas n. CAAE: 80613217.0.0000.5404, e as participantes concordaram em responder ao questionário, via Termo de Consentimento de Livre Esclarecimento. O questionário online foi enviado a um representante de cada equipe participante da LBF 2018, que deveria encaminhá-lo para as atletas, tendo este procedimento o conhecimento e consentimento da LBF, conforme descreve os termos do CEP. 


\subsection{PARTICIPANTES}

$\mathrm{Na}$ temporada 2018, a LBF foi composta por nove equipes e todas foram incluídas na pesquisa. Dentre elas, seis (67\%) equipes eram do estado de São Paulo, uma (11\%) do Maranhão, uma (11\%) de Santa Catarina e uma (11\%) de Pernambuco. Foram inscritas 118 atletas na liga, sendo que 13 estrangeiras não pertenciam ao universo de interesse deste estudo, com enfoque nas atletas brasileiras. Desta forma, de 105 atletas, 57 participaram da pesquisa, representando $54,3 \%$ do total de brasileiras. A idade média das participantes se situou em 25,9 \pm 6,6 anos. A descrição das atletas e equipes participantes da pesquisa estão apresentadas na Tabela 1.

Tabela 1 - Equipes e atletas participantes da pesquisa

\begin{tabular}{lllcc}
\hline Equipe & Cidade & Estado & $\begin{array}{c}\text { Frequência } \\
\text { absoluta }\end{array}$ & $\begin{array}{c}\text { Frequência } \\
\text { (\%) }\end{array}$ \\
\hline Presidente Venceslau & Presidente Venceslau & São Paulo & 9 & $16 \%$ \\
Uninassau Recife & Recife & Pernambuco & 9 & $16 \%$ \\
Santo André & Santo André & São Paulo & 1 & $2 \%$ \\
Blumenau & Blumenau & Santa Catarina & 2 & $4 \%$ \\
Catanduva & Catanduva & São Paulo & 10 & $18 \%$ \\
Campinas & Campinas & São Paulo & 2 & $4 \%$ \\
Ituano & Itu & São Paulo & 11 & $19 \%$ \\
São Bernardo & São Bernardo & São Paulo & 10 & $18 \%$ \\
Sampaio Corrêa & São Luís & Maranhão & 3 & $\mathbf{5 \%}$ \\
\hline Total & & & $\mathbf{5 7}$ & $\mathbf{1 0 0 \%}$ \\
\hline
\end{tabular}

Fonte: os autores

\subsection{ANÁLISE DE DADOS}

A análise dos dados se deu por meio de estatística descritiva (frequência absoluta, mínima, máxima, média, desvio padrão e porcentagem), também aplicada por Cunha et al. (2017) e Beneli (2018), mostrando-se adequada e satisfatória para a descrição de perfil de atletas de uma liga esportiva. A partir dos temas do questionário, agrupamos os dados em quatro áreas temáticas, determinadas a priori: (1) experiência esportiva - remete às faixas etárias, locais e contextos onde as atletas realizaram desde sua iniciação no basquetebol até a participação em competições adultas; (2) convocação para seleções nacionais - apresenta as atletas que integraram as seleções brasileiras, tanto de base quanto adulta; (3) características socioeconômicas - expõe dados a respeito da percepção das atletas sobre sua classe social, sua remuneração, auxílios financeiros e nível de escolaridade, perpassando desde a base até o profissional2; (4) pós-carreira - aborda as intenções iniciais para o processo de descontinuidade, na expectativa de verificar se as atletas têm alguma preocupação com o tema, incluindo idade e atividades profissionais a serem exercidas.

2 Visando identificar a dinâmica de classe social das atletas, percebemos que não existe um critério consensual de definição dessas classes no contexto brasileiro (PAIVA, 2012). Conforme Rosa (2015), essa estratificação considera critérios objetivos ou subjetivos, sendo estes últimos especialmente voltados à opinião dos indivíduos sobre o estrato ao qual pertencem. Considerando que este estudo busca compreender a perspectiva das atletas, adotamos o critério subjetivo. Em revisão acerca do tema, Rosa (2015) aponta que as classes sociais são comumente divididas em classe baixa, classe média baixa, classe média, classe média alta e classe alta. Portanto, implementamos essas alternativas no questionário, visando proporcionar mais clareza para que as atletas se posicionem sobre este contexto 


\section{RESULTADOS}

Os resultados são apresentados dentro das áreas temáticas em que a pesquisa se organizou, sendo apresentados na seguinte ordem: (1) experiência esportiva; (2) convocação para seleções nacionais; (3) características socioeconômicas; e (4) póscarreira.

\subsection{EXPERIÊNCIA ESPORTIVA}

A Tabela 2 apresenta as faixas etárias nas quais as atletas iniciaram a prática, a competição e a competição na categoria adulta. Destacamos que tanto o início da prática quanto da competição se deu entre 9 e 12 anos, e que a maioria iniciou as competições na categoria adulta antes de completar 18 anos.

Tabela 2 - Faixas etárias, início da prática e da competição no basquetebol das atletas participantes.

\begin{tabular}{lccc}
\hline Faixa Etária & $\mathbf{5}$ a $\mathbf{8}$ anos & $\mathbf{9}$ a $\mathbf{1 2}$ anos & $\mathbf{1 3}$ a $\mathbf{1 5}$ anos \\
\hline Início da prática & $19,3 \%$ & $57,9 \%$ & $22,8 \%$ \\
Início em competição & $10,5 \%$ & $49,1 \%$ & $40,4 \%$ \\
Faixa Etária & $\leq 17$ anos & 18 a 20 anos & $\geq 20$ anos \\
Início em competição na categoria adulta & $70,2 \%$ & $26,3 \%$ & $3,5 \%$ \\
\hline
\end{tabular}

Fonte: Os autores.

A Tabela 3 mostra os locais (região e estado) de nascimento das atletas, do início da prática e da competição no basquetebol. O estado de São Paulo aparece como principal centro na iniciação e desenvolvimento de atletas do basquetebol feminino no Brasil, pois mais de $70 \%$ das atletas participantes iniciaram a prática da modalidade e em competições neste estado. Por consequência, a Região Sudeste se destaca. Salientamos a ausência de atletas na LBF que nasceram ou que tiveram o primeiro contato com a modalidade e competições na Região Norte do país.

Tabela 3 - Distribuição geográfica do nascimento, início de prática e início em competições das atletas participantes.

\begin{tabular}{llccc}
\hline Região & Estado & Nascimento & Início da prática & Início em competição \\
\hline \multirow{2}{*}{ Nordeste } & Maranhão & $2(2,0 \%)$ & $2(4,0 \%)$ & $2(4,0 \%)$ \\
& Pernambuco & $1(2,0 \%)$ & $1(2,0 \%)$ & $1(2,0 \%)$ \\
\hline \multirow{3}{*}{ Centro-Oeste } & Distrito Federal & $1(2,0 \%)$ & $1(2,0 \%)$ & $1(2,0 \%)$ \\
& Goiás & $2(4,0 \%)$ & $2(4,0 \%)$ & $0(0,0 \%)$ \\
& Mato Grosso do Sul & $1(2,0 \%)$ & $1(2,0 \%)$ & $1(2,0 \%)$ \\
\hline \multirow{3}{*}{ Sudeste } & Minas Gerais & $1(2,0 \%)$ & $1(2,0 \%)$ & $1(2,0 \%)$ \\
& Rio de Janeiro & $3(5,0 \%)$ & $4(7,0 \%)$ & $4(7,0 \%)$ \\
& São Paulo & $39(68,0 \%)$ & $40(70,0 \%)$ & $42(74,0 \%)$ \\
\multirow{3}{*}{ Sul } & Paraná & $3(5,0 \%)$ & $1(2,0 \%)$ & $1(2,0 \%)$ \\
& Rio Grande do Sul & $2(4,0 \%)$ & $2(4,0 \%)$ & $2(4,0 \%)$ \\
& Santa Catarina & $2(4,0 \%)$ & $2(4,0 \%)$ & $2(4,0 \%)$ \\
\hline
\end{tabular}

Fonte: Os autores.

Os contextos em que as participantes iniciaram a prática do basquetebol são ilustrados na Figura 1. Dentre seis diferentes contextos, ganham destaque escola, 
clube e prefeitura, respectivamente, representando o conjunto de onde quase $80 \%$ das atletas tiveram seu primeiro contato com a modalidade.

Figura 1 - Contexto de início da prática do basquetebol das atletas participantes.

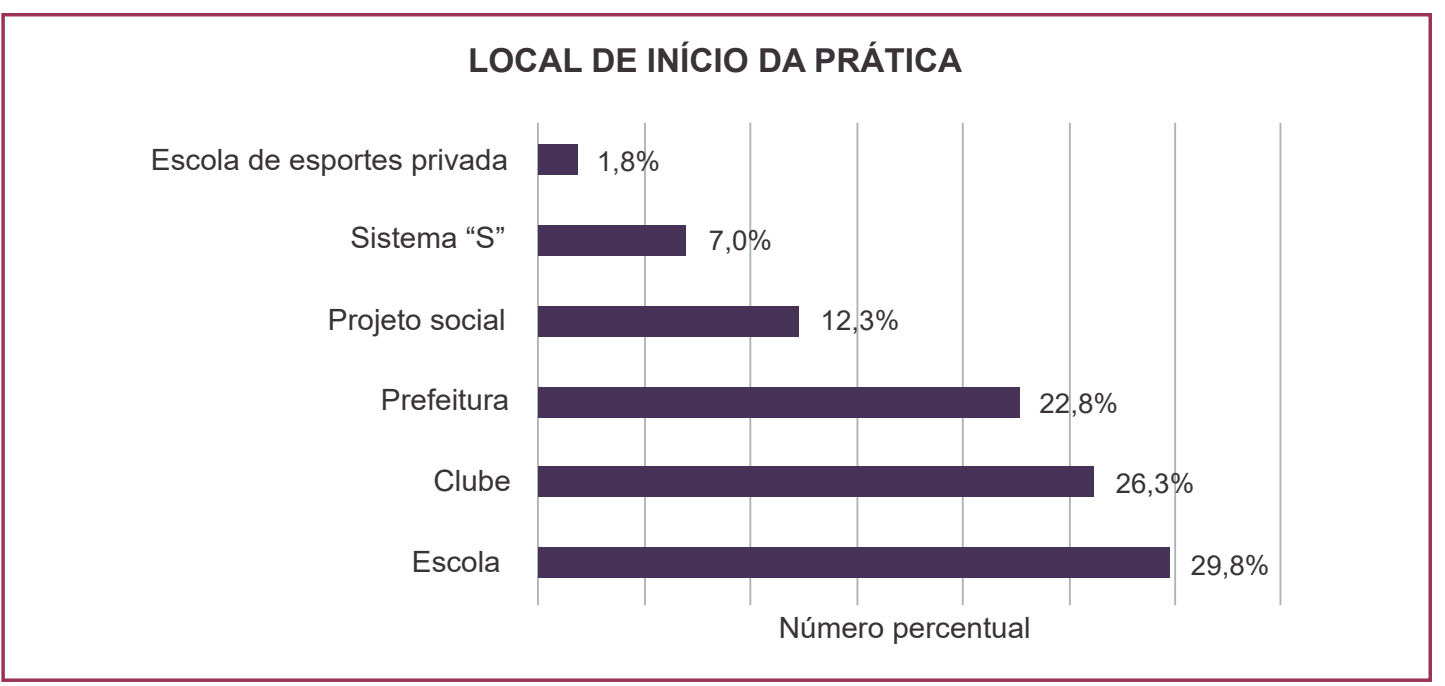

Fonte: Os autores.

\subsection{CONVOCAÇÕES PARA A SELEÇÃO NACIONAL DE BASE E ADULTA}

A maioria das atletas $(78,9 \%)$ foi convocada para seleções das categorias de base e apenas uma atleta participou da seleção adulta sem ter participado de seleções de base. Já na seleção nacional adulta, a minoria $(29,8 \%)$ das participantes teve alguma convocação.

\subsection{CARACTERÍSTICAS SOCIOECONÔMICAS}

Os dados do estudo foram coletados em 2018, quando o salário mínimo no Brasil era de $\mathrm{R} \$ 954,00$. Mais da metade das atletas da Liga $(57,9 \%)$ recebia até dois salários mínimos por mês, sendo que quase um terço das atletas $(31,6 \%)$ recebia até $\mathrm{R} \$ 1.000,00$ por mês, próximo ao equivalente a um salário mínimo (Figura 2).

Figura 2 - Faixa salarial das atletas participantes.

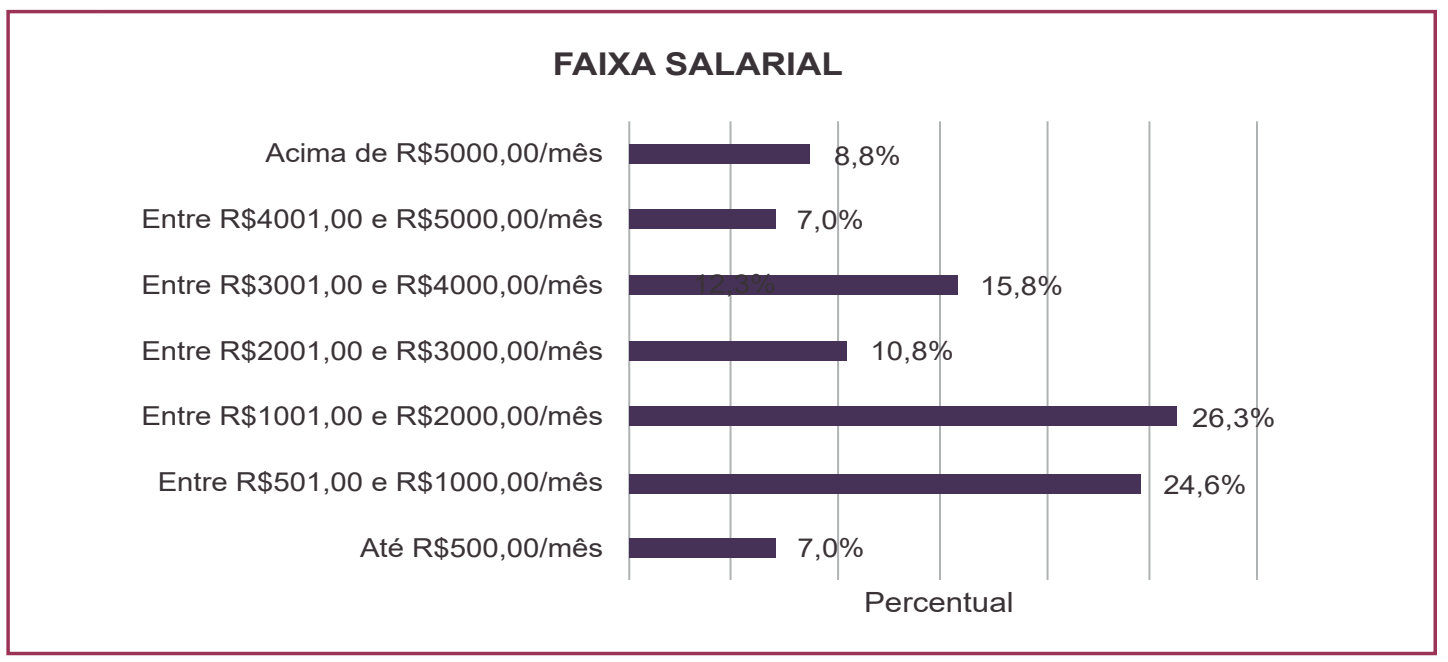

Fonte: Os autores. 
A percepção das atletas sobre a própria classe social, antes e depois de começarem a competir, pode ser visualizada na Figura 3. Os dados apontam que parte das atletas percebeu uma mobilidade social ao longo da carreira de basquetebol, visto que o percentual de atletas que declararam estar nas classes baixa e média baixa $(54,4 \%)$ diminuiu para $33,3 \%$ atualmente, elevando o percentual das atletas na classe média de $28,1 \%$ para $50,9 \%$. O número de atletas nas classes alta e média alta praticamente não sofreu alteração entre o início da carreira e a fase atual, mas observa-se que, somadas, as classes média, média alta e alta abrigavam apenas $45,7 \%$ das atletas no início da carreira, ao passo que abrigam atualmente $66,7 \%$

Figura 3 - Percepção das atletas participantes quanto a classe social quando iniciaram na competição e a atual.

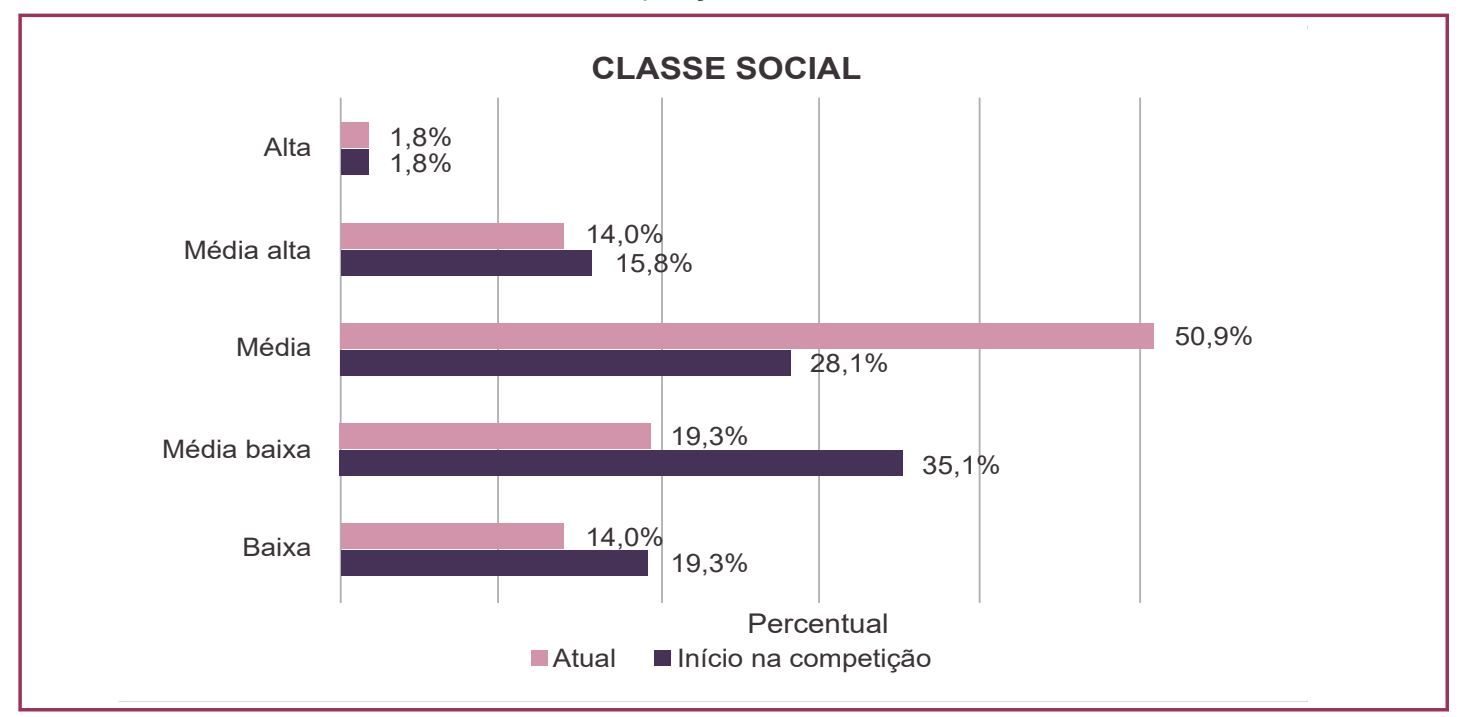

Fonte: Os autores.

Os auxílios recebidos durante as categorias de base e adulta são apresentados na Figura 4. Nas categorias de base, as possibilidades de bolsas para as atletas foram maiores que os auxílios de vales-transporte e alimentação, sendo marcante a queda nas bolsas de estudo na categoria adulta.

Figura 4 - Auxílios recebidos pelas atletas participantes nas categorias de base e no adulto.

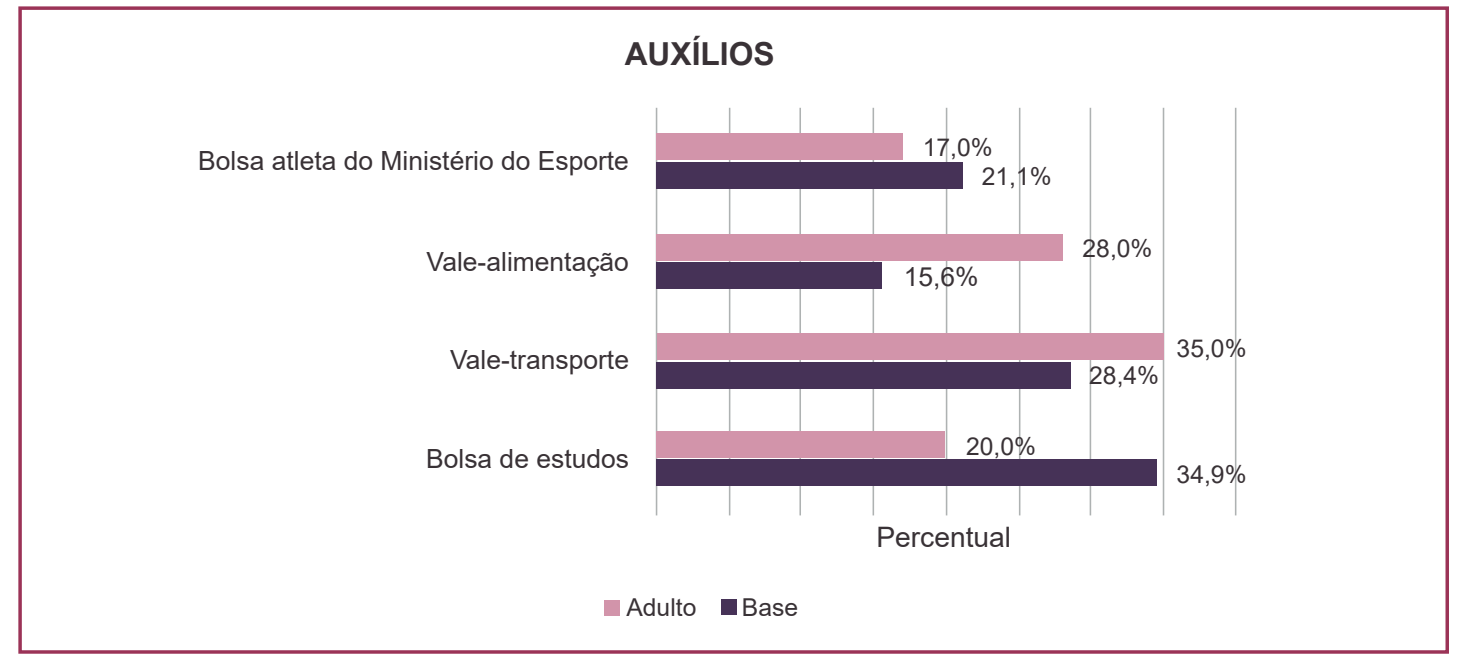

Fonte: Os autores. 
Em relação aos níveis de escolaridade, utilizamos as categorias propostas pelo Instituto Brasileiro de Geografia e Pesquisa (PNAD, 2019), para que os níveis de instrução fossem ponderados de forma coerente a partir de grupos de faixas etárias. Apenas uma das atletas tem menos de 18 anos e se encontra cursando o ensino médio. Os dados referentes às demais atletas são apresentados nas Figuras 5 e 6.

Figura 5 - Escolaridade das atletas participantes de 18 a 24 anos.

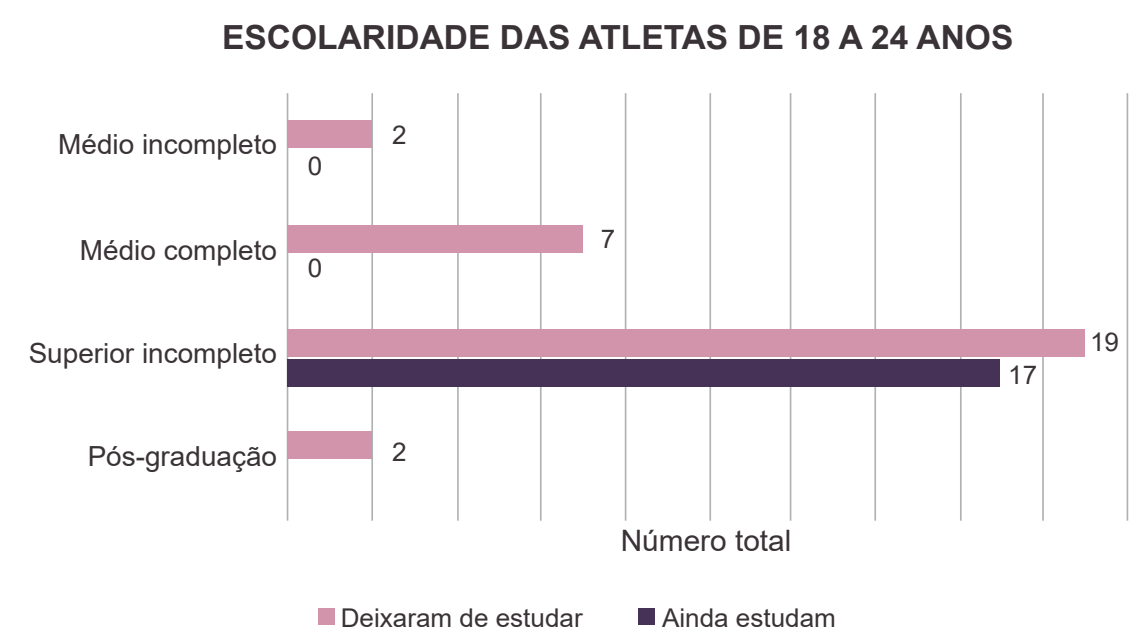

Fonte: Os autores.

Figura 6 - Escolaridade das atletas participantes de 25 anos ou mais.

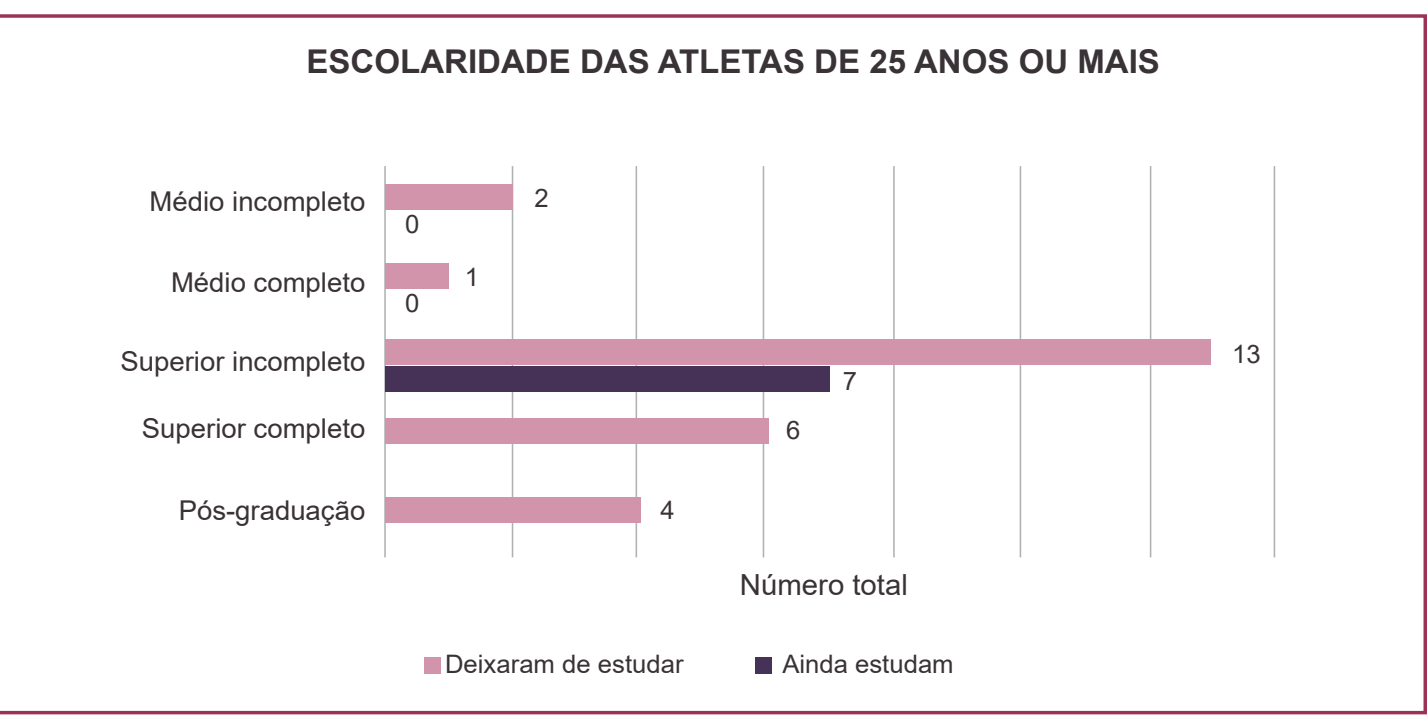

Fonte: Os autores.

\subsection{PÓS-CARREIRA DE ATLETA}

$\mathrm{Na}$ Figura 7 são apresentadas as faixas etárias em que as atletas planejam encerrar a carreira. Percebemos que mais de $60 \%$ delas pretendem encerrar a carreira após os 31 anos e apenas 12,3\% pretendem continuar jogando após completar 40 anos. 
Figura 7 - Faixa etária que as atletas participantes planejam encerrar a carreira.

\section{PLANEJAMENTO DE ENCERRAMENTO DA CARREIRA ESPORTIVA}

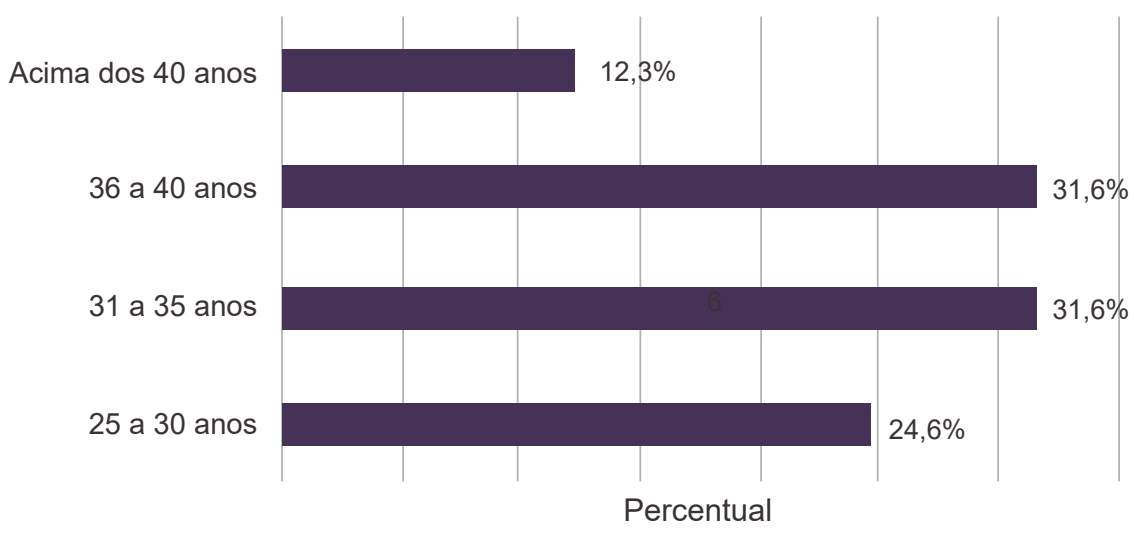

Fontes: Os autores.

Os dados sobre o planejamento profissional após encerrarem suas carreiras como atletas de basquetebol podem ser observados na Figura 8. As respostas das atletas foram agrupadas em seis áreas: esporte, saúde e estética, serviço público, gestão e empreendedorismo, em branco (não responderam) e outros.

Figura 8 - Planos das atletas participantes para o pós-carreira.

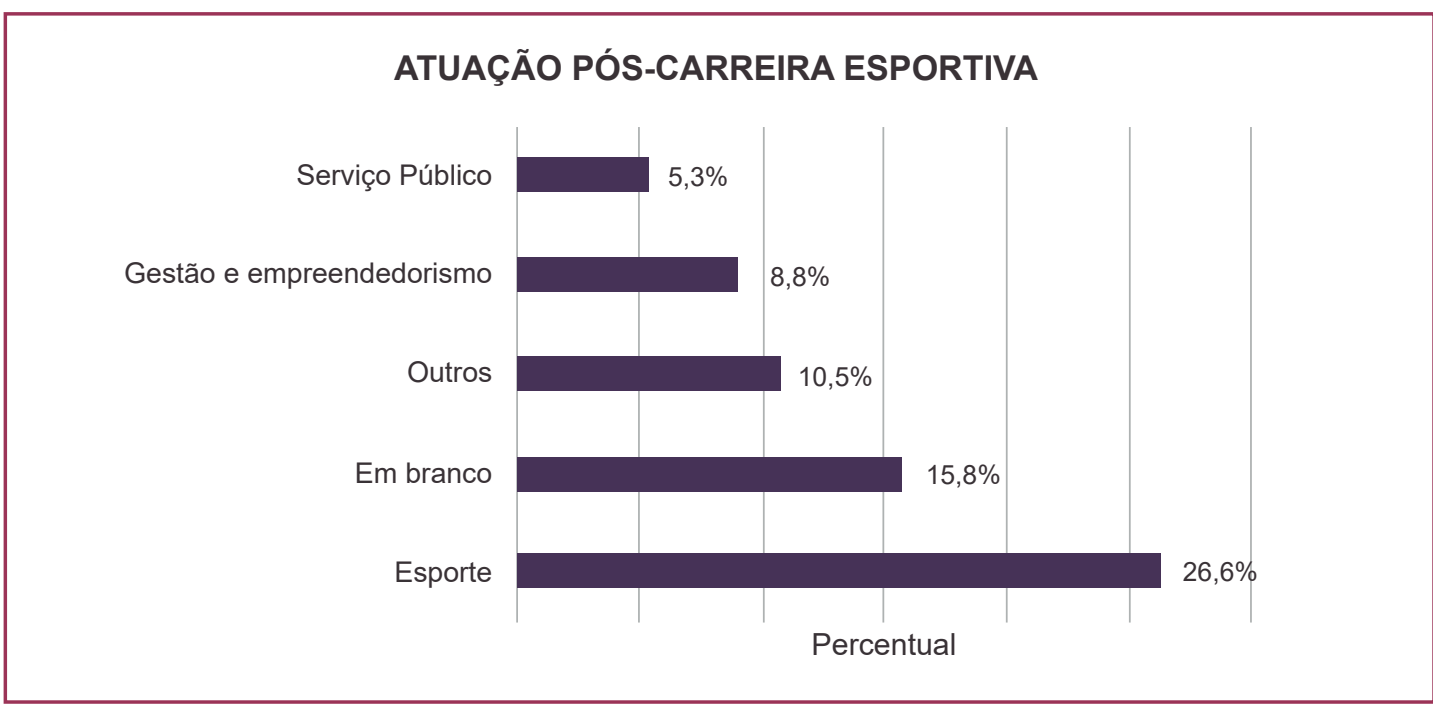

Fonte: Os autores.

\section{DISCUSSÃO}

Descrever o perfil e trajetória de atletas da LBF nos permite compreender onde e com quais recursos essas mulheres se constituíram atletas da principal competição de basquete feminino do Brasil, sendo possível identificar desde o local e momento do início da prática, até os dados sobre a condição financeira ou escolar já no esporte de elite (CUNHA et al., 2017; GALATTI et al., 2017). Assim, na sequência são discutidos os dados acerca da experiência esportiva até a categoria adulta, sobre 
as convocações para seleção brasileira de base e adulta, dados sociodemográficos percebidos já como mulheres adultas na principal liga de basquetebol do Brasil e o planejamento de encerramento de carreira.

\subsection{TRAJETÓRIA ESPORTIVA ATÉ A CATEGORIA ADULTA}

São Paulo se confirmou como o principal estado no desenvolvimento de atletas de basquetebol feminino no país, tanto em relação à origem das atletas, como quanto ao local de início da prática e da participação em competições, a exemplo do que identificaram Guedes (2009), Beneli, Galatti e Montagner (2017) e Galatti et al. (2019). A primeira explicação é histórica, pela inclusão do basquetebol no currículo da Escola Normal de São Paulo, frequentada por alunas de famílias da capital e interior, já em 1906 (GUEDES, 2009). Outros fatores estão associados ao fato de São Paulo ser o estado com maiores oportunidades para as jovens na modalidade, com oferta mais recorrente de campeonatos estaduais para as categorias de base e maior número de clubes participantes, como, por exemplo, as ligas regionais, os campeonatos metropolitanos, entre outros (ANTONELLI et al., 2012; AZEVEDO, 2014). Dentre as regiões, o Sudeste se destaca como origem mais recorrente das atletas, o que pode ser extrapolado também para os atletas de basquetebol masculino (CUNHA et al., 2017), bem como atletas medalhistas olímpicos brasileiros(as) em geral (TOZETTO et al., 2017).

Como o principal contexto de início de prática, foi relatada a escola, seguida por clubes e prefeituras. Este cenário é discrepante do encontrado no basquetebol masculino, em que a maioria dos atletas participantes da liga nacional (NBB) teve o primeiro contato com a prática da modalidade nos clubes (CUNHA et al., 2017). Porém, mesmo no contexto escolar, é comum que as meninas sejam percebidas por professores(as) como menos habilidosas e interessadas pelo basquetebol que seus colegas do gênero masculino (SEVERINO; GONÇALVES; DARIDO, 2015), o que pode desfavorecer o estímulo à prática. Além disso, apesar dos clubes serem reconhecidos como o principal centro para o desenvolvimento da modalidade no país (MARTINS, 2013), o resultado encontrado neste estudo sugere que estas instituições investem prioritariamente no basquetebol masculino, confirmando as disparidades existentes no fomento ao esporte feminino no Brasil (GOELLNER, 2014; PEREIRA, 2019). As prefeituras também se destacaram como local de início da prática por atletas da liga feminina, o que nos remete à recomendação de Folle et al. (2017) para o estímulo de parcerias público-privadas como um caminho interessante de gestão do basquetebol feminino.

Em relação à idade de início da prática de basquetebol e da participação em competições, os resultados encontrados confirmaram a tendência observada por Beneli (2018) e Galatti et al. (2019): em média, houve um intervalo de 13 meses entre o início da prática e o início da competição, indicando que as atletas de basquetebol têm uma iniciação esportiva de curta duração e logo já são inseridas no ambiente de competição. A inserção na competição após um ano de prática não é necessariamente um problema, mas recomendamos que novos estudos se aprofundem em conhecer as características e formato das competições, assim como do treinamento nesta 
etapa. Isto porque a maioria das jogadoras iniciou a prática e a competição durante a infância (5 a 12 anos), podendo ser um indício de especialização precoce.

A especialização precoce se refere ao treinamento sistematizado em um único esporte antes dos 13 anos (aproximadamente), com alta concentração de prática deliberada, ou seja, atividades focadas no desenvolvimento de habilidades específicas e pouca diversificação, diversão e ausência de atividades lideradas pelas próprias crianças (CÔTÉ et al., 2009; CÔTÉ; BAKER; ALBERNETHY, 2007). De acordo com a revisão de Waldron et al. (2019), dentre as possíveis implicações estão o abandono do esporte, devido à falta de divertimento e pressão por rendimento, o risco de lesões por estresse físico e o estresse psicológico crônico. Neste estudo investigamos as atletas que chegaram à LBF, mas a especialização precoce pode estar associada à evasão de meninas da prática do basquetebol e, consequentemente, menor número de praticantes na idade adulta (BENELI; GALATTI; MONTAGNER, 2017), logo, sugerimos novos estudos com mulheres que foram atletas de basquetebol na infância e juventude, mas que não seguiram na modalidade.

\subsection{CONVOCAÇÕES PARA A SELEÇÃO NACIONAL DE BASE E ADULTA}

A maioria das atletas $(79,8 \%)$ passou pelas seleções nacionais de base, o que pode ser consequência do baixo número de jovens atletas de basquetebol feminino, fazendo com que as mesmas poucas atletas passem pelos processos de formação e de prática na liga adulta (GALATTI et al., 2015). Destacamos que não investigamos as passagens por seleções estaduais, pois o campeonato brasileiro de basquete de base foi extinto em 2016 (BALASSIANO, 2016) e, desde então, os dados acerca das equipes estaduais e do campeonato brasileiro foram excluídos do site da Confederação Brasileira de Basquete. Entretanto, compreendemos que este tipo de campeonato é importante para o desenvolvimento do basquete feminino brasileiro, pois uma boa estrutura de competição nacional permite que jovens talentos se desenvolvam, treinem e vivenciem modelos e níveis diferenciados de competições (DE BOSSCHER et al., 2006; MAZZEI et al., 2015).

A oportunidade de jogar em uma seleção nacional de base pode ter contribuído para que as atletas investigadas permanecessem no esporte e chegassem à LBF. $29,8 \%$ delas foram convocadas para a seleção nacional adulta, cenário semelhante ao basquetebol masculino (CUNHA et al., 2017). Apenas uma atleta chegou à seleção adulta sem passagem por seleções nacionais de base. Esse dado pode sugerir que o processo de preparação das atletas nas seleções de base pode estar contribuindo com o sucesso em atingir a seleção adulta. Entretanto, visto que a maioria das participantes iniciou a prática e a competição no basquetebol em um único estado, São Paulo, e que no Brasil não há uma política nacional de identificação e desenvolvimento de talentos no esporte, tampouco no basquetebol feminino, é possível entender que as convocações para as seleções nacionais, tanto de base quanto adulta, não são resultados de programas consistentes e planejados, mas retratam investimento em poucas atletas de elite (MAZZEI et al., 2015).

Outros estudos confirmam que a identificação e desenvolvimento de talentos esportivos no Brasil é um dos pilares menos organizados nos estados e municípios 
(BOJIKIAN; BOHME, 2015). A grande extensão territorial, a desigualdade entre regiões, estados e municípios, e a desconexão das agências promotoras do esporte são considerados fatores que agravam essas circunstâncias e que podem reforçar a concentração de atletas de basquetebol feminino em São Paulo. O estado tem cidades com IDH e desenvolvimento econômico dentre os maiores do país, oferecendo outras possibilidades como a universidade ou suporte familiar para manter-se no esporte, visto que a remuneração identificada nesta investigação é baixa.

Além disso, o desenvolvimento esportivo e a formação de atletas constitui um processo multifatorial em longo prazo, no qual a participação sistemática em competições como meio de incremento de desempenho deveria estar articulada com outros pilares. Entre eles, o suporte financeiro à modalidade esportiva e o apoio às atletas e ao pós-carreira, assentados sobre uma ampla base de promoção da participação esportiva formal e não formal (DE BOSSCHER et al., 2006), visto que é imensamente reduzido o número de jovens que participam do esporte de base e seguem carreira como atleta de elite. Daí ser fundamental considerar a iniciação e formação esportiva como um processo educacional com finalidades ampliadas da experiência esportiva em suas múltiplas possibilidades (GALATTI et al., 2016).

\subsection{CARACTERÍSTICAS SOCIOECONÔMICAS}

Um terço das atletas recebia, aproximadamente, até um salário mínimo $(\mathrm{R} \$$ 954,00), nos valores de 2018 e $58 \%$ das atletas recebia aproximadamente dois salários mínimos $(R \$ 2.000,00)$. A baixa remuneração é característica não apenas do basquetebol, mas da maioria das modalidades esportivas praticadas por mulheres no Brasil.

Lima (2018a) aponta a existência de uma defasagem dos valores salariais de mulheres em relação aos homens, sendo que o mercado de trabalho no contexto esportivo para elas é reduzido e desigual (PAIM; STREY, 2006). Pelas remunerações apontadas, podemos perceber que a prática do basquetebol feminino na elite nacional não permite às atletas condições de alcançar sua independência financeira, o que presume considerar manter-se nos estudos em nível superior e perspectivar uma segunda carreira após a curta carreira esportiva (MELO; RUBIO, 2017).

O futebol masculino pode nos ajudar a aprofundar a reflexão sobre a questão salarial. No Brasil são cerca de 800 clubes de futebol oferecendo entre 10 e 15 mil postos de trabalho para atletas de futebol (DAMO, 2007). Dados divulgados pela CBF em 2009 indicavam que $84 \%$ dos atletas recebia até $\mathrm{R} \$ 1.000,00$ por mês, cerca de $13 \%$ recebia entre $\mathrm{R} \$ 1.000,00$ e $\mathrm{R} \$ 9.000,00$, e apenas 3\% recebiam salário mensal maior que R $\$ 9.000,00$ (SOARES et al., 2011). Esses números indicam que, inclusive na modalidade mais popular e almejada como carreira esportiva no Brasil, ao menos entre homens, a realidade do atleta de elite é muito difícil. Além das baixas condições financeiras, enfrentam relações de trabalho precárias, alojamentos em condições muitas vezes insalubres, e afastamento de outras possibilidades educacionais, inclusive da escola, na busca pelo profissionalismo (DAMO, 2007). Tega (2014) estima que por volta de uma em cada 3 mil crianças que participam das categorias de base chegará a ser atleta de futebol. Mesmo diante desses números, o futebol é 
visto como uma oportunidade ímpar de ascensão social, sobretudo entre jovens das classes mais populares (GONZÁLEZ; BORGES; SFALCIN, 2016), nos remetendo a discutir a percepção de classe social entre as atletas de basquetebol.

Em relação à classe social no início da prática, a maioria das atletas se declarou pertencente às classes média baixa ou baixa, semelhante ao contexto de atletas da seleção nacional (BENELI; GALATTI; MONTAGNER, 2017) e de muitas modalidades no Brasil, inclusive o futebol masculino (MARQUES; SAMULSKI, 2009). Porém, chama atenção o volume de atletas que, na sua própria percepção, afirma ter ascendido para a classe média. Isso pode ter reflexo na manutenção da prática esportiva, já que o reconhecimento financeiro é um dos pontos importantes para a continuação dos atletas no esporte (SAMULSKI et al., 2009). Fato que também pode reforçar a ideia de que atletas jovens de nível econômico menor tenham um interesse maior em permanecer na modalidade, pela possibilidade de ascensão social através do esporte (GUEDES; SILVÉRIO NETTO, 2013). Mesmo com esse contexto financeiro desfavorável, cerca de $20 \%$ das atletas perceberam mobilidade social positiva durante a carreira esportiva. Contudo, o número de equipes e campeonatos de nível profissional, como o da LBF, são mais escassos em comparação ao masculino. Assim, entendemos que impulsionar o basquete feminino passa por questões de valorização e ampliação dos espaços de prática e formação para as meninas e mulheres no basquetebol.

Tal percepção de mobilidade social, entretanto, não pode ser tomada como um resultado real positivo da participação esportiva. Uma análise mais objetiva das faixas salariais das atletas em relação à estratificação social de acordo com os critérios de renda per capita medida por salários mínimos utilizados pelo IBGE sugere que a mobilidade social das atletas ocorreu principalmente dentro da base da pirâmide social que caracteriza a classe trabalhadora pobre (POCHMANN, 2012), visto que, de acordo com a faixa salarial declarada pelas atletas, atualmente, a maioria delas ainda se encontra nas classes mais baixas, compondo a classe proletária (SINGER, 2015). Há que ser considerado que neste estudo foram acessadas apenas a faixa salarial das atletas e suas percepções subjetivas sobre seus enquadramentos nas classes sociais. Entretanto, não foram analisados outros dados como a renda familiar per capita, que poderia oferecer um quadro mais preciso sobre as classes sociais em que encontram as atletas da LBF.

Além da questão salarial, também foram analisados os auxílios recebidos, que mostram as categorias de base com maior quantidade de bolsa-atleta e de bolsas de estudos em relação à categoria adulta, apresentando esta, por outro lado, maior número de atletas recebendo vale-alimentação e transporte. Tais diferenças entre os apoios financeiros oferecidos na base e na categoria adulta parecem corresponder às necessidades específicas de cada etapa da carreira esportiva das atletas. Na adolescência, as bolsas de estudo e bolsa-atletas são meios importantes de sustentação da permanência das meninas no esporte, especialmente ao se considerar que a maioria delas veio de classes baixas e não teria condições próprias de financiar seu desenvolvimento esportivo. Também no handebol feminino, LIMA (2018b) identificou que os auxílios foram fundamentais para a permanência no 
esporte até a excelência: sem os auxílios, possivelmente as atletas não teriam se mantido na prática esportiva. Já na fase adulta, a vinculação das atletas com suas equipes tende a ser orientada por relações de trabalho e, neste sentido, justifica-se que a oferta de vale-alimentação e transporte, ainda mais quando tais condições de trabalho são precárias, com sugerem os baixos salários de boa parte delas.

Referente aos níveis de escolaridade, as atletas da LBF se encontram acima das médias nacionais, em comparação estabelecida a partir da Pesquisa Nacional de Amostra por Domicílio de 2018 (PNAD, 2019). Nas faixas etárias de 18 a 24 anos, apenas $8 \%$ dos(as) brasileiros(as) alcançaram o ensino superior e, dentre estes, apenas $16,5 \%$ concluíram. Na faixa etária de 25 anos ou mais, apenas $21 \%$ dos(as) brasileiros(as) atingiram o ensino superior e, destes, 38\% o concluíram. Entre as atletas da LBF, chegaram ao ensino superior $70 \%$ das atletas de 18 a 24 anos, e $88 \%$ de 25 anos ou mais, sendo que vinte atletas receberam bolsa de estudos no ensino superior. Ademais, 48,1\% dos(as) brasileiros(as) interrompem seus estudos antes de ingressarem ensino médio, ao passo que todas as atletas da LBF superam este nível de escolaridade.

Neste contexto, percebemos a relação positiva entre o basquetebol e a escolaridade, possivelmente favorecida pelas bolsas de estudo oferecidas às atletas. Mascarin, Vicentini e Marques (2019) observaram cenário semelhante no futsal feminino de elite e, em estudo com 444 atletas olímpicas brasileiras, Melo e Rubio (2017) identificaram que 50\% delas concluíram o ensino superior, mostrando que a participação no esporte de elite tende a favorecer melhor escolaridade entre mulheres brasileiras. A escolaridade deveria ser ponto fulcral no desenvolvimento de carreiras esportivas, conciliando contexto de prática esportiva com experiências formativas ampliadas promotoras de desenvolvimento humano (GALATTI, 2017).

A melhor escolaridade das atletas de basquetebol pode estar relacionada às bolsas escolares como um subterfúgio para salários mais baixos para atletas jovens. Ao olharmos novamente para o futebol masculino, o cenário imediatista de ajudas de custo indica remuneração entre 200 e 400 dólares entre as categorias infantil e juniores (DAMO, 2005), o que leva a um cenário distinto do basquetebol feminino: as famílias tendem a incentivar mais a carreira de futebol que os estudos, já que este auxílio pode representar renda superior a dos familiares responsáveis pelo garoto, gerando ainda uma despreocupação com uma segunda carreira (RIAL, 2006). No basquetebol feminino há relatos do impacto das atletas no sustento de suas famílias (GALATTI et al., 2019) já na fase de manutenção da carreira, o que pode indicar que as bolsas escolares e universitárias ajudam a manter a atleta nos estudos, mas não permitem autonomia financeira.

\subsection{PÓS-CARREIRA}

Quando se trata dos planos pós-carreira, a maior parte das atletas pretende seguir no ramo esportivo, principalmente na área de Educação Física, continuando a relação profissional estreita com o esporte, tendência confirmada em pesquisa com ex-atletas de basquetebol realizada por Galatti et al. (2019). Esta tendência converge ao confirmado por Melo e Rubio (2017), em estudo que indica que 65\% das ex- 
atletas olímpicas investigadas que concluíram a graduação atuam na área esportiva. O fim da carreira esportiva pode acontecer por diferentes fatores, como idade, lesão ou vontade da atleta, e cada fator influenciará de uma forma na sequência da vida e na aposentadoria (SANTOS; ALEXANDRINO, 2015). Com isso, torna-se importante que atletas tenham um plano pós-carreira considerando cada situação, de forma que a transição nessa fase seja positiva. De fato, a maioria das participantes relataram planejar seguir carreira em alguma área do mercado, no entanto, não investigamos o quão preparadas elas se sentem com seu plano de inserção, tampouco se recebem suporte de políticas esportivas pós-carreira.

Apesar de a maioria relatar ter um plano pós-carreira, uma parcela das atletas da LBF neste estudo (16\%) deixou o campo em branco. A falta de planejamento e suporte nessa fase de transição da carreira pode acarretar problemas psicológicos, emocionais, físicos e/ou sociais, por exemplo, a crise identitária (PARK; LAVALLEE; TOD, 2013), e inclusive favorecer o uso de drogas e álcool (FISHER; WRISBERG, 2007). Em estudo com atletas brasileiros de elite, Santos, Nogueira e Böhme (2016) identificaram que $75 \%$ dos participantes afirmaram que a assistência pós-carreira esportiva é insuficientemente desenvolvida e $78 \%$ enfatizam que as perspectivas de carreira após a aposentadoria são um sério problema. Como identificado no estudo de Mazzei et al. (2015), a política esportiva do Brasil foi classificada bem abaixo de outros países, como Canadá e Itália, no quesito suporte aos atletas e pós-carreira. O suporte ao atleta de elite não está relacionado somente ao apoio financeiro, mas também estruturas, acompanhamento de profissionais de diferentes áreas e ações de educação (MAZZEI et al., 2015). Desta forma, programas sobre gestão de póscarreira, por exemplo, podem auxiliar nessa fase de transição e no planejamento da aposentadoria.

\section{CONSIDERAÇÕES FINAIS}

Esta pesquisa investigou as atletas de uma liga brasileira de esporte feminino, a Liga de Basquete Feminino (LBF), descrevendo características sociodemográficas ao longo da carreira. Ao analisar o perfil e trajetória das atletas participantes deste estudo, encontramos um cenário ambíguo de oportunidades, restrições e precariedades no percurso das atletas no basquetebol feminino brasileiro.

Em geral, as oportunidades de prática do basquetebol feminino no Brasil concentram-se fortemente no estado de São Paulo. Tal constatação aponta para a falta de fomento ao desenvolvimento de atletas em nível nacional, o que limita o acesso à prática por milhares de meninas de outras regiões do Brasil, prejudicando a formação e o desenvolvimento de atletas em longo prazo. Logo, faz falta um projeto de desenvolvimento da modalidade, que poderia ser capitaneado pela Confederação Brasileira de Basquetebol em articulação com as federações estaduais, LBF e clubes, entre outras instituições. O Comitê Olímpico Brasileiro é também uma instituição em potencial no foco de recuperação dos resultados internacionais, inclusive com algumas ações já desenhadas pelo Instituto Olímpico Brasileiro, que poderiam orientar as ações no basquetebol feminino. 
Se, por um lado, a carreira no basquetebol parece ter favorecido o desenvolvimento das atletas da LBF participantes do estudo nas categorias de base pelo acesso à educação formal que resultou em maior nível de escolaridade do que a população brasileira em geral, por outro, a maioria das atletas da principal liga de basquete brasileiro tem módicos salários, reafirmando a baixa atratividade da carreira esportiva no Brasil em geral, e particularmente na modalidade. O que coloca em xeque, mais uma vez, a máxima de que o esporte promove ascensão social.

Para além da promoção do desenvolvimento esportivo em si, em busca de recuperar o status de potência mundial de basquetebol feminino, promover a modalidade no Brasil, democratizar seu acesso em outras regiões, equalizar as disparidades existentes entre basquete feminino e masculino e proporcionar condições de trabalho mais dignas para as atletas, são exemplos de caminhos possíveis para que a modalidade contribua para o desenvolvimento humano, social e econômico das mulheres praticantes de basquetebol no país.

\section{REFERÊNCIAS}

ALFERMANN, Dorothee; STAMBULOVA, Natalia. Career transitions and career termination. In: TENENBAUM, Gershon; EKLUND, Robert. Handbook of sport psychology. Hoboke: John Wiley \&Sons, 2007. p. 712-733.

ALVES-MAZZOTTI, Alda Judith. Usos e abusos dos estudos de caso. Cadernos de pesquisa, v. 36, n. 129, p. 637-651, 2006.

ANDRADE, Maria Margarida (org.). Introdução à metodologia do trabalho científico. 9. ed. São Paulo: Atlas, 2009.

ANTONELLI, Mariana et al. Pedagogia do esporte e basquetebol: considerações para a elaboração de programa esportivo a partir do clube Divino Salvador, Jundiaí-SP. Conexões, v. 10, n. 2, p. 49-65, 2012. Disponível em: https://periodicos.sbu.unicamp.br/ojs/index.php/ conexoes/article/view/8637674. Acesso em: 29 abr. 2020.

AZEVEDO, Marcio Faria de. Conciliações entre formação esportiva e formação escolar: um estudo das seleções brasileiras masculinas de basquetebol de base. 2014. $127 \mathrm{f}$. Dissertação (Mestrado em Educação Física) - Centro de Educação Física e Desportos, Universidade Federal do Espírito Santo, Vitória, 2014.

BARREIRA, Júlia et al. Produção acadêmica em futebol e futsal feminino: estado da arte dos artigos científicos nacionais na área da educação física. Movimento, v. 24, n. 2, p. 607612, 2018. Disponível em: https://seer.ufrgs.br/Movimento/article/view/80030. Acesso em: 29 abr. 2020.

BALASSIANO, Fábio. A um mês da Olimpíada, CBB vive o caos nas divisões de base. Bala na cesta, 2016. Disponível em: https://balanacesta.blogosfera.uol.com.br/2016/07/09/a-ummes-da-olimpiada-cbb-vive-o-caos-nas-divisoes-de-base/. Acesso em: 15 de out. 2020.

BENELI, Leandro de Melo. Trajetória esportiva de atletas de alto rendimento no basquetebol masculino e feminino no Brasil: estudo retrospectivo. Tese (Doutorado em Educação Física) - Faculdade de Educação Física, Universidade Estadual de Campinas, Campinas, 2018. 
BENELI, Leandro de Melo; GALATTI, Larissa Rafaela; MONTAGNER, Paulo Cesar. Analysis of social-sportive characteristics of Brazil women's national basketball team players. Revista de Psicología del Deporte, v. 26, n. 3, p. 133-137, 2017. Disponível em: https://www.rpdonline.com/article/view/v26-n3-beneli-galatti-montagner. Acesso em: 19 jun. 2019.

BRASIL. : Presidência da República. Decreto n. ${ }^{\circ} 3.199$, de 14 de abril de 1941. Estabelece as bases de organização dos desportos em todo o país. Diário Oficial da República Federativa do Brasil, Brasília, DF, 1941. Disponível em: http://www.planalto.gov.br/ ccivil 03/Decreto-Lei/1937-1946/Del3199.htm\#: :text=exclusivamente\%20de\%20 amadores.-.Art. \%C3\%A0s\%20entidades\%20desportivas $\% 20$ do\%20pa\%C3\%ADs. Acesso em: 29 abr. 2020.

BOJIKIAN, Luciane.; BÓHME, Maria Tereza Silveira. Pilar 4 - Identificação e desenvolvimento de talentos esportivos. In: BÖHME, M. T. S.; BASTOS, F.C. Relatório de Pesquisas em Estados e Capitais Brasileiros. São Paulo:Phorte, 2015. p.77-96.

CAFRUNI, Cristina; MARQUES, António; GAYA, Adroaldo. Análise da carreira desportiva de atletas das regiões sul e sudeste do Brasil: Estudo dos resultados desportivos nas etapas de formação. Revista portuguesa de ciências do desporto, v. 6, n. 1, p. 55-64, 2006.

COLLET, Carine et al. Atividades de prática deliberada e jogo deliberado na formação esportiva de atletas de elite do voleibol: diferenças entre os sexos. Revista E-Balonmano. com: Revista de Ciencias del Deporte, v. 13, n. 2, p. 95-104, 2017. Disponível em: http:// www.e-balonmano.com/ojs/index.php/revista/article/view/388/pdf. Acesso em: 29 abr. 2020.

CÔTÉ, Jean et al. The benefits of sampling sports during childhood. Physical \& Health Education Journal, v. 74, n. 4, p. 6-11, 2009. Disponível em: https://www.researchgate. net/profile/Jean_Cote3/publication/236002408_The_Benefits_of_Sampling_Sports_During Childhood/links/55b7785d08ae092e9657175c/The-Benefits-of-Sampling-Sports-DuringChildhood.pdf. Acesso em: 15 out. 2020.

CÔTÉ, Jean; BAKER, Joseph; ALBERNETHY, Bruce. Practice and play in the development of sport expertise. In: TENENBAUM, Gershon; EKLUND, Robert. Handbook of sport psychology. Hoboke: John Wiley \&Sons, 2007. p. 184-202.

CÔTÉ, Jean; ERICSSON, K. Anders; LAW, Madelyn P. Tracing the development of athletes using retrospective interview methods: A proposed interview and validation procedure for reported information. Journal of applied sport psychology, v. 17, n. 1, p. 1-19, 2005.

CÔTÉ, Jean; TURNNIDGE, Jennifer; EVANS, Blair. The dynamic process

of development through sport. Kinesiologia Slovenica, v. 20, n. 3, p. 14-26, 2014.

Disponível em: https://www.kinsi.si/mma/099200_264.pdf/201805221111470032/. Acesso em: 15 out. 2020.

CUNHA, Luiza Darido et al. Trayectoria de los jugadores de baloncesto del nuevo baloncesto Brasil. Cuadernos de Psicología del Deporte, v. 17, n. 3, p. 119-128, 2017. Disponível em: https://revistas.um.es/cpd/article/view/313891. Acesso em: 29 jun. 2019.

DAMO, Arlei Sander. Do dom à profissão: uma etnografia do futebol de espetáculo a partir da formação de jogadores no Brasil e na França. 2005. 435 f. Tese (Doutorado em Antropologia Social) - Instituto de Filosofia e Ciências Humanas, Universidade Federal do Rio Grande do Sul, Porto Alegre, 2005.

DAMO, Arlei Sander. Do dom à profissão: a formação de futebolistas no Brasil e na França. São Paulo: Hucitec, 2007. 
DE BOSSCHER, Veerle et al. A conceptual framework for analysing sports policy factors leading to international sporting success. European Sport Management Quarterly, v. 6, n. 2, p. 185-215, 2006. Disponível em: https://www.tandfonline.com/doi/ abs/10.1080/16184740600955087. Acesso em: 16 out. 2020.

FIBA. INTERNATIONAL BASKETBALL FEDERATION. Ranking women's Olympic qualifying tournaments. Disponível em: http://www.fiba.basketball/rankingwomen. Acesso em: 29 abr. 2020.

FISHER, Leslee; WRISBERG, Craig. How to handle athletes transitioning out of sport. Athletic Therapy Today, v. 12, n. 7, p. 49-50, 2007. Disponível em: https://journals. humankinetics.com/view/journals/ijatt/12/2/article-p49.xml. Acesso em: 16 out. 2020.

FOLLE, Alexandra et al. Female basketball athlete development environment: proposed guidelines and success factors. Educación Física y Ciencia, v. 19, n. 2, p. 1-15. 2017. Disponível em: https://doi.org/10.24215/23142561e035. Acesso em: 29 jun. 2019.

GALATTI, Larissa Rafaela. AFEs, Desenvolvimento Humano e Esporte de Alto Rendimento. In: PNUD Brasil. Relatório Nacional de Desenvolvimento Humano. 2017. v.1.

GALATTI, Larissa Rafaela et al. Atletas de Elite: aspectos relevantes na formação em longo prazo. In: GALATTI, Larissa Rafaela; SCAGLIA, Alcides; MONTAGENER, Paulo Cesar; PAES, Roberto Rodrigues. Desenvolvimento de treinadores e atletas - Pedagogia do Esporte. Campinas: Editora da UNICAMP, 2017. p. 211-234.

GALATTI, Larissa Rafaela et al. Determinantes de excelência no basquetebol feminino: as conquistas da seleção Brasileira na perspectiva das atletas. Revista de Educação Física/ UEM, v. 26, n. 4, p. 621-632, 2015. Disponível em: http://www.periodicos.uem.br/ojs/index. php/RevEducFis/article/view/26424. Acesso em: 20 jun. 2019.

GALATTI, Larissa Rafaela et al. Excellence in women basketball: sport career development of world champions and Olympic medalists Brazilian athletes. Revista de Psicología del Deporte, v. 28, n. 3, p. 17-23, 2019. Disponível em: https://www.rpdonline.com/article/view/ v28-n3-galatti-marques-barros-etal. Acesso em: 10 jul. 2019.

GALATTI, Larissa Rafaela et al. Fostering elite athlete development and recreational sport participation: A successful club environment. Motricidade, v. 12, n. 3, p. 20-31, 2016. Disponível em: http://www.scielo.mec.pt/scielo.php?script=sci arttext\&pid=S1646107X2016000300004. Acesso em: 20 abr. 2020.

GIGLIO, Sergio Settani et al. Desafios e percalços da inserção da mulher nos Jogos Olímpicos (1894-1965). Recorde: Revista de História do Esporte, v. 11, n. 1, p. 1-22, 2018. Disponível em: https://revistas.ufrj.br/index.php/Recorde/article/view/17868. Acesso em: 15 abr. 2020.

GIL, Antonio Carlos. Estudo de caso: fundamentação científica - subsídios para coleta e análise de dados - como redigir o relatório. São Paulo: Atlas, 2009.

GITTI, Vivian da Silva; BASTOS, Flávia da Cunha. Estrutura Organizacional e perfil do gestor de equipes participantes da Liga de Basquete Feminino (LBF) 2011/2012. PODIUM: Sport, Leisure and Tourism Review, v. 2, n. 2, p. 53-75, 2013. Disponível em: https://periodicos. uninove.br/index.php?journal=podium\&page $=$ article\&op=view\&path $\% 5 B \% 5 D=9502$. Acesso em: 12 abr. 2018.

GOELLNER, Silvana Vilodre. As mulheres, o esporte e o direito de ser. Revista do Observatório Brasil de Igualdade de Gênero, v. 4, n. 6, p. 15-18, 2014. Disponível em: http://www.observatoriodegenero.gov.br/menu/publicacoes. Acesso em: 29 abr. 2020. 
GONZÁLEZ, Fernando Jaime; BORGES, Robson Machado; SFALCIN, Alexandre. O sonho acabou! Abandono da carreira esportiva de atletas profissionais de futebol. Revista Corpoconsciência, v. 19, n. 1, p. 11-21, 2016. Disponível em: https://periodicoscientificos. ufmt.br/ojs/index.php/corpoconsciencia/article/view/3797. Acesso em: 16 jan. 2021.

GUEDES, Claudia Maria. Mulheres à cesta: o basquetebol feminino no Brasil (1892-1971). São Paulo: Miss Lily, 2009.

GUEDES, Dartagnan Pinto; SILVÉRIO NETTO, José Evaristo. Motivos para a prática de esportes em atletas jovens e fatores associados. Revista de Educação Física/UEM, v. 24, n. 1, p. 21-31, 2013. Disponível em: http://www.periodicos.uem.br/ojs/index.php/RevEducFis/ article/view/14695. Acesso em: 10 mar. 2020.

LIMA, Camila Rodrigues Neves de Almeida. Gênero, trabalho e cidadania: função igual, tratamento salarial desigual. Revista Estudos Feministas, v. 26, n. 3, e47164, 2018a. Disponível em: http://dx.doi.org/10.1590/1806-9584-2018v26n347164. Acesso em: 10 ago. 2019.

LIMA, Leilane Alves de. Carreira esportiva: um estudo com atletas de excelência. 2018b. 111f. Dissertação (Mestrado em Educação Física) - Faculdade de Educação Física, Universidade Estadual de Campinas, Campinas, 2018.

MARQUES, Renato Francisco Rodrigues et al. Formação de jogadores profissionais de voleibol: relações entre atletas de elite e a especialização precoce. Revista Brasileira de Educação Física e Esporte, v. 28, n. 2, p. 293-304, 2014.

MARQUES, Maurício Pimenta; SAMULSKI, Dietmar Martin. Análise da carreira esportiva de jovens atletas de futebol na transição da fase amadora para a fase profissional: escolaridade, iniciação, contexto sócio-familiar e planejamento da carreira. Revista Brasileira de Educação Física e Esporte, v. 23, n. 2, p. 103-119, 2009. Disponível em: http://www.revistas.usp.br/rbefe/article/view/16714. Acesso em: 23 mar. 2020.

MARTINS, Luciana Nogueira. Futsal Feminino: Perfil das atletas nos jogos de Minas Gerais 2012 e implicações pedagógicas. Revista Brasileira de Futsal e Futebol, Edição Especial: Pedagogia do Esporte, v. 5, n. 18, p. 331-340, 2013. Disponível em: http://www.rbff.com.br/ index.php/rbff/article/view/163. Acesso em: 20 abr. 2019.

MASCARIN, Rafaela Bevilaqua; VICENTINI, Lucas; MARQUES, Renato Francisco Rodrigues. Brazilian women elite futsal players' career development: diversified experiences and late sport specialization. Motriz: Revista de Educação Física, v. 25, n. 2, 2019. Disponível em: https://www.scielo.br/scielo.php?script=sci arttext\&pid=S1980-65742019000200311. Acesso em: 13 out. 2020.

MAZZEI, Leandro Carlos et al. High performance sport in Brazil Structure and policies comparison with the international context. Gestion y Politica Publica, volumen temático, p. 83-111, 2015. Disponível em: https://www.redalyc.org/pdf/133/13343542004.pdf. Acesso em: 16 out. 2020.

MELO, Gislane Ferreira; RUBIO, Katia. Mulheres atletas olímpicas brasileiras: início e final de carreira por modalidade esportiva. Revista Brasileira de Ciência e Movimento, v. 25, n. 4, p. 104-116, 2017. Disponível em: https://portalrevistas.ucb.br/index.php/RBCM/article/ view/7672. Acesso em: 13 out. 2020.

MORALES JÚNIOR, Valter Ruiz et al. The relative age effect on Brazilian elite futsal: men and women scenarios. Motriz, v. 23, n. 3, e101704, 2017. Disponível em: http://dx.doi. org/10.1590/s1980-6574201700030016. Acesso em: 10 ago. 2019. 
PAIM, Maria Cristina Chimelo; STREY, Marlene Neves. Marcas da violência de gênero contra a mulher no contexto esportivo. Revista Digital, ano 11, n. 103, 2006. Disponível em: https://www.efdeportes.com/efd103/genero.htm. Acesso em: 19 abr. 2019.

PAIVA, Guilherme França dos Santos. Consumo e critérios de classificação socioeconômica: um estudo aplicado à pesquisa de orçamentos familiares. 2012. $129 \mathrm{f}$. Dissertação (Mestrado em Estudos Populacionais e Pesquisa Social) - Escola Nacional de Ciências Estatísticas, Instituto Brasileiro de Geografia e Estatística, Rio de Janeiro, 2012.

PARK, Sunghee; LAVALLEE, David; TOD, David. Athletes' career transition out of sport: a systematic review. International Review of Sport and Exercise Psychology, v. 6, n. 1, p. 22-53, 2013. Disponível em: https://www.tandfonline.com/doi/full/10.1080/175098 4X.2012.687053. Acesso em: 15 out. 2020.

PASSERO, Julia Gravena et al. Gender (in) equality: a longitudinal analysis of women's participation in coaching and referee positions in the Brazilian Women's Basketball League (2010-2017). Cuadernos de Psicologia del Deporte, v. 19, n. 1, p. 252-261, 2019. Disponível em: https://revistas.um.es/cpd/article/view/348611. Acesso em: 10 ago. 2019.

PEREIRA, Adriana Bernardes. A mulher e o esporte: do desafio da desigualdade ao desacerto com as questões de gênero. In: RUBIO, Katia; CAMILO, Juliana A. de Oliveira. Psicologia social do esporte. São Paulo: Laços, 2019. p. 36-665.

PNAD. PESQUISA NACIONAL POR AMOSTRA DE DOMICÍLIOS. Educação. 2019. Disponível em: https://biblioteca.ibge.gov.br/visualizacao/livros/liv101657_informativo.pdf. Acesso em: 24 jun. 2019.

PNUD. PROGRAMA DAS NAÇÕES UNIDAS PARA O DESENVOLVIMENTO. Relatório de Desenvolvimento Humano Nacional - Movimento é Vida: atividades físicas e esportivas para todas as pessoas. 2017. Disponível em: https://www.ufrgs.br/redecedesrs/bibliotecal movimentoevida. Acesso em: 24 jun. 2019.

POCHMANN, M. Nova classe média?: o trabalho na base social da pirâmide brasileira. São Paulo: Boitempo. 2012.

RIAL, Carmen. Jogadores brasileiros na Espanha: emigrantes porém... Revista de Dialectología y Tradiciones Populares, v. 61, n. 2, p. 163-190, 2006. Disponível em: https://pdfs.semanticscholar.org/c880/059be99bc81175db921a6f4d5a4fc500ff94.pdf. Acesso em: 16 jan. 2021.

ROCHA, Priscila Garcia Marques da; SANTOS, Edivando Souza dos. O abandono da modalidade esportiva na transição da categoria juvenil para adulto: estudo com talentos do atletismo. Revista da Educação Física/UEM, v. 21, n. 1, p. 69-77, 2010. Disponível em: http://www.periodicos.uem.br/ojs/index.php/RevEducFis/article/view/6912. Acesso em: 13 out. 2020.

ROSA, Thiago Mendes. Ensaios sobre o consumo. 2015. 125 f. Dissertação (Mestrado em Economia) - Setor de Ciência Sociais Aplicadas, Universidade Federal do Paraná, Curitiba, 2015.

SAMULSKI, Dietmar Martin et al. Análise das transições das carreiras de ex-atletas de alto nível. Motriz, v. 15, n. 2, p. 310-317, 2009. Disponível em: http://www.periodicos. rc.biblioteca.unesp.br/index.php/motriz/article/view/2499. Acesso em: 18 jun. 2019.

SANTOS Ana Lúcia Padrão; ALEXANDRINO, Roseane Raduan. Desenvolvimento da carreira do atleta: análise das fases e transições. Conexões, v. 13, n. 2, p. 185-205, 2015. 
SANTOS, Ana Lúcia Padrão dos; NOGUEIRA, Maressa D'Paula G. Rosa;

BÖHME, Maria Tereza Silveira. Elite athletes' perception of retirement support

systems. International Journal of Physical Education, Sports and Health,

v. 3, n. 1, p. 138-139, 2016. Disponível em: https://www.kheljournal.com/

archives/?year=2016\&vol=3\&issue=1\&part=D\&Articleld=291. Acesso em: 16 out. 2020 .

SEVERINO, Claudio Delunardo; GONÇALVES, Francisco José Miranda; DARIDO, Suraya

Cristina. A prática do basquetebol por meninas nas aulas de educação física escolar no município de Volta Redonda: a visão dos professores. Motricidade, v. 11, n. 2, p. 36-47, 2015. Disponível em: http://dx.doi.org/10.6063/motricidade.3473. Acesso em: 23 jun. 2019.

SINGER, André. Quatro notas sobre as classes sociais nos dez anos de lulismo. Psicologia USP, v. 26, n.1. p. 7-14, 2015. Disponível em: https://www.scielo.br/pdf/pusp/v26n1/01036564-pusp-26-01-00007.pdf. Acesso em: 13 out. 2020.

SOARES, Antonio Jorge Gonçalves et al. Jogadores de futebol no Brasil: mercado, formação de atletas e escola. Revista Brasileira de Ciências do Esporte, v. 33, n. 4, p. 905-921, 2011. Disponível em: https://www.scielo.br/scielo.php?pid=S0101$\underline{32892011000400008 \& s c r i p t=s c i}$ abstract\&tlng=pt. Acesso em: 16 jan. 2021.

SOUZA, Ana Claudia Ferreira de; MARTINS, Mariana Zuaneti. O paradoxo da profissionalização do futsal feminino no brasil: entre o esporte e outra carreira. Pensar a Prática, v. 21, n. 1, p. 26-39, 2018. Disponível em: https://www.revistas.ufg.br/fef/ article/view/45075\#: :text=Para\%20as $\% 20$ mulheres\%2C\%20a\%20carreira, de $\% 20$ mudan\%C3\%A7a\%20social\%20para\%20elas. Acesso em: 13 out. 2020.

STAMBULOVA, Natalia et al. ISSP position stand: career development and transitions of athletes. International Journal of Sport and Exercise Psychology, v. 7, n. 4, p. 395-412, 2009. Disponível em: https://www.tandfonline.com/doi/ abs/10.1080/1612197X.2009.9671916?needAccess=true\&journalCode=rijs20. Acesso em: 13 out. 2020.

TEGA, Eduardo. Futebol e sustentabilidade: Eduardo Tega - TEDxInatel. 2014. Disponível em: https://www.youtube.com/watch?v=ImHRzXfzlYY. Acesso em: 27 nov. 2020.

TOZETTO, Alexandre Vinicius Bobato et al. Birthplace and birthdate of Brazilian Olympic medalists. Revista Brasileira de Cineantropometria \& Desempenho Humano, v. 19, n. 3, p. 364-373, 2017. Disponível em: http://dx.doi.org/10.5007/1980-0037.2017v19n3p364. Acesso em: 20 jun. 2019.

WALDRON, Shelby et al. The costs and benefits of early sport specialization: a critical review of literature. Quest, v. 72, n. 1, p. 1-18, 2019. https://www.tandfonline.com/doi/ abs/10.1080/00336297.2019.1580205?journalCode=uqst20. Acesso em: 15 out. 2020.

YIN. Robert K. Estudo de caso: planejamento e métodos. 3 ed. Porto Alegre: Bookman, 2005. 
Abstract: Starting in the 2000s, we observed a challenging scenario for the development of female basketball athletes in Brazil. In 2010, the Women's Basketball League (LBF) was created to restructure that sport in the country. The aim of the study was to describe LBF 2018 athletes' trajectories and sociodemographic profiles throughout their careers. Data were collected through an online questionnaire voluntarily answered by 57 athletes (average age $25.9 \pm 6.6$ years). The school was the main place for their first contact with basketball. Most athletes $(79 \%)$ played for junior National Teams and 30\% reached the adult National Team. Brazil's Southeast stood out as the main region for practicing female basketball. A career in basketball creates a perception of improvement in terms of social class. Finally, the group of athletes had higher levels of education than the average Brazilian population.

Keywords: Basketball. Women. Professional practice.

Resumen: Después del año 2000, observamos un escenario desafiador para el desarrollo de mujeres atletas de baloncesto en Brasil. En 2010, se crea la Liga de Baloncesto Femenino (LBF) para contribuir con la reestructuración de esa modalidad deportiva en el país. El objetivo del estudio fue investigar índices deportivos y sociodemográficos a lo largo de la carrera de atletas de la LBF en 2018. Los datos se recolectaron mediante un cuestionario online que respondieron voluntariamente 57 atletas (edad media 25,9 $\pm 6,6$ años). La escuela fue el principal lugar de primer contacto con ese deporte. La mayoría de las atletas $(79 \%)$ fue convocadas para selecciones y el 30\% llegó a la selección adulta. La región Sudeste se destacó como la principal región donde se practica esta modalidad. La carrera en el baloncesto proporcionó una percepción de mejoría de clase social. Finalmente, el grupo de atletas presentó niveles de escolaridad más altos que la media de la población brasileña.

Palabras clave: Baloncesto. Mujeres. Práctica Profesional. 


\section{LICENÇA DE USO}

Este é um artigo publicado em acesso aberto (Open Access) sob a licença Creative Commons Atribuição 4.0 Internacional (CC BY 4.0), que permite uso, distribuição e reprodução em qualquer meio, desde que o trabalho original seja corretamente citado. Mais informações em: http://creativecommons.org/licenses/by/4.0

\section{CONFLITO DE INTERESSES}

Os autores declararam que não existe nenhum conflito de interesses neste trabalho.

\section{CONTRIBUIÇÕES AUTORAIS}

Larissa Rafaela Galatti: Conceituação, Metodologia, Investigação, Recursos, Escrita Escrita - Revisão e Edição, Visualização, Supervisão, Administração do Projeto e Obtenção de Financiamento. É co-executora do convênio da FCA/Unicamp com a LBF, participante de todas as etapas, desde as reuniões preliminares com a liga, executou ou acompanhou cada etapa do processo, tendo experiência prévia com a aplicação do instrumento. É a responsável metodológica, conceitual e pela revisão final do texto.

Cesar Vieira Marques Filho: Análise Formal, Investigação, Escrita - Primeira Redação, análise de dados. Atuou em todo o processo, com destaque para análise de dados e redação preliminar do texto.

Yura Yuka Sato dos Santos: Conceituação, Análise Formal, Investigação, Escrita - Revisão e Edição, Atuou em todo o processo, com destaque para discussão e conferência de dados.

Guilherme Watoniki: Análise Formal, Escrita - Primeira Redação, análise de dados. Atuou em todo o processo, com destaque para análise de dados e redação preliminar dos resultados.

Paula Korsakas: Conceituação, Metodologia, Redação, Escrita - Revisão e Edição. Participou de todo o estudo, desde a concepção e refinamento do instrumento. Revisora conceitual, sobretudo do tema esporte, mulheres e crianças.

Luciano Allegretti Mercadante: Metodologia, Recursos, Escrita - Revisão e Edição, Visualização, Supervisão, Administração do Projeto e Obtenção de Financiamento. É executor do convênio da FCA/Unicamp com a LBF, participante de todas as etapas, desde as reuniões preliminares com a liga, até cada etapa da elaboração deste estudo.

\section{FINANCIAMENTO}

O presente trabalho foi realizado com apoio do Convênio de Cooperação entre a UNCAMP e LBF, número 36p-18381/2017 e Conselho Nacional de Desenvolvimento Científico e Tecnológico, (CNPq) através das bolsas de estudos.

\section{ÉTICA DE PESQUISA}

O projeto de pesquisa foi encaminhado e aprovado pelo Comitê de Ética em Pesquisa da Universidade Estadual de Campinas (UNICAMP), n. CAAE: 80613217.0.0000.5404. 


\section{COMO REFERENCIAR}

GALATTI, Larissa Rafaela; MARQUES FILHO, Cesar Vieira; SANTOS, Yura Yuka Sato dos; WATONIKI, Guilherme; KORSAKAS, Paula; MERCADANTE, Luciano Allegretti. Trajetória no basquetebol e perfil sociodemográfico de atletas brasileiras ao longo da carreira: um estudo com a liga de basquete feminino (LBF). Movimento (Porto Alegre), v.27, e26014, jan./dez. 2021. Disponível em: https:// seer.ufrgs.br/Movimento/article/view/106017. Acesso em: [dia] [mês abreviado]. [ano]. DOI: https://doi.org/10.22456/1982-8918.106017

\section{RESPONSABILIDADE EDITORIAL}

Alex Branco Fraga*, Elisandro Schultz Wittizorecki*, Ivone Job*, Mauro Myskiw*, Raquel da Silveira*

*Universidade Federal do Rio Grande do Sul, Escola de Educação Física, Fisioterapia e Dança, Porto Alegre, RS, Brasil. 